$\underline{\text { Original }}$

\title{
Identification of Yellow-Pigmented Bacteria Isolated from Hospital Tap Water in Japan and Their Chlorine Resistance
}

\author{
KATSUNORI FURUHATA ${ }^{1}{ }^{*}$, YUKO KATO $^{2}$, KEIICHI GOTO $^{2}$, KEIKO SAITOU $^{3}$, \\ JUN-ICHI SUGIYAMA ${ }^{3}$, MOTONOBU HARA ${ }^{4}$, AND MASAHUMI FUKUYAMA ${ }^{1}$ \\ ${ }^{1}$ School of Environmental Health, Azabu University, \\ 1-17-71, Fuchinobe, Sagamihara, Kanagawa 229-8501, Japan \\ ${ }^{2}$ Food Research Laboratories, Mitsui Norin Co., Ltd., \\ 223-1, Miyahara, Fujieda, Shizuoka 426-0133, Japan \\ ${ }^{3}$ Research and Investigation Department, Building Management Education Center, \\ 1-4-28, Mita, Minato, Tokyo 108-0073, Japan \\ ${ }^{4}$ School of Veterinary Medicine, Azabu University, \\ 1-17-71, Fuchinobe, Sagamihara, Kanagawa 229-8501, Japan \\ Received 23 October, 2006/Accepted 4 February, 2007
}

Twenty-five yellow chromogenic strains isolated from hospital tap water samples collected nationwide were identified by partial 16S rDNA sequencing. In addition, the chlorine resistance of the isolates was experimentally investigated. The results showed that of the strains tested, 12 strains $(48.0 \%)$ were Sphingomonas ursincola/natatoria, which was most frequently identified, followed by 2 strains (8.0\%) of Mycobacterium frederiksbergense and 1 strain (4.0\%) each of Sphingomonas adhaesiva, Sphingopyxis witflariensis and Porphyrobacter donghaensis. The other strains were not identified clearly but they belonged to the order of Alphaproteobacteria. On the other hand, the identification results by sequencing and biochemical property testing were not consistent in any of the strains, showing that it was difficult to accurately identify the yellow chromogenic bacteria in tap water based on only their biochemical properties.

When the 25 isolates were exposed to $0.1 \mathrm{mg} / \mathrm{I}$ residual free chlorine for 1 minute, 22 isolates $(88.0 \%)$ survived. When the CT (Concentration Time) value killing $99.99 \%$ of the bacteria was investigated in 6 of these survivors, M. frederiksbergense ( $Y-1$ strain) was most resistant to chlorine with the CT value of $32 \mathrm{mg} \cdot \mathrm{min} / \mathrm{I}$, followed by S. ursincola/natatoria ( $Y$ 7 strain) with the CT value of $3.3 \mathrm{mg} \cdot \mathrm{min} / \mathrm{l}$. The CT values of Y-5 (Sphingomonas sp.), Y-27 (S. ursincola/natatoria) and Y-21 (Asticacaulis sp.) were within the range of $0.9-0.1 \mathrm{mg} \cdot \mathrm{min}$ /I. Of the 6 strains, $S$. adhaesiva (Y-10) showed the weakest resistance with the CT value of $0.03 \mathrm{mg} \cdot \mathrm{min} / \mathrm{l}$. It was clarified that most yellow chromogenic bacteria isolated from hospital tap water were Sphingomonas spp., and these bacteria were experimentally resistant to chlorine.

Key words : Yellow-pigment/Sphingomonas sp./Tap water/Hospital/Identification/ Chlorine resistance.

${ }^{*}$ Corresponding author. Tel : +81-42-754-7111, Fax : +8142-754-6215. 


\section{INTRODUCTION}

Since washing hands with sterile water before surgery is not required and a switch to tap water had been approved in Japan, we investigated oligotrophic bacteria in hospital tap water in Japan (Furuhata and Fukuyama, 2006). The result showed that oligotrophic bacteria were isolated from about $80 \%$ of hospital tap water samples collected nationwide, and no significant regional difference was noted. The residual chlorine concentration in tap water from which oligotrophic bacteria were isolated was $0.1-0.8$ $\mathrm{mg} / \mathrm{l}$, and oligotrophic bacteria were isolated from $80 \%$ of tap water samples containing residual free chlorine, although the chlorine concentration varied. Most isolates were gram-negative rods, but only about $40 \%$ of these could be identified clearly by biochemical property testing alone (Methylobacterium spp. and Pseudomonas spp.).

Furthermore, many of the other unidentified isolates produced water-insoluble yellow pigments.

In 1977, Holmes et al. performed a taxonomic study of yellow chromogenic gram-negative rods derived from human clinical specimens and hospital environments, and proposed a new species, Pseudomonas paucimobilis. O'Brien (1992) investigated biochemical properties of yellow chromogenic non-fermentative gram-negative rods isolated from disinfected tap water, but he could not identify the bacteria and reported it as a new Pseudomonas species. Since these yellow chromogenic bacteria have been suggested to be causative bacteria of opportunistic infections, a taxonomic study of the unidentified isolates from hospital tap water has become necessary.

In this study, yellow chromogenic bacteria isolated from hospital tap water were subjected to identification by genetic analysis. Since many yellow chromogenic bacteria were isolated from hospital tap water containing residual chlorine, the chlorine resistance of the isolates was also experimentally confirmed.

\section{MATERIALS AND METHODS}

\section{Bacterial strains and cultivation}

In 2004, 271 samples of tap water in hospitals in 18 prefectures of Japan were cultured on R2A agar medium $(0.5 \mathrm{~g}$ pepton, $0.5 \mathrm{~g}$ yeast extract, $0.5 \mathrm{~g}$ casamino $\cdot$ acid, $0.5 \mathrm{~g}$ glucose, $0.5 \mathrm{~g}$ soluble starch, $0.3 \mathrm{~g}$ $\mathrm{K}_{2} \mathrm{HPO}_{4}, 0.05 \mathrm{~g} \mathrm{MgSO}_{4} \cdot 7 \mathrm{H}_{2} \mathrm{O}, 0.3 \mathrm{~g}$ sodium pyruvate and $15 \mathrm{~g}$ agar per liter, pH7.0-7.4; Wako Pure Chemical Industries, Ltd., Osaka, Japan) at $30^{\circ} \mathrm{C}$ for 7 days. In total, 25 colonies with yellow pigmentation
TABLE 1. Isolated regions of test strains, and the concentration of free residual chlorine when isolated from the tap water in hospitals.

\begin{tabular}{|c|c|c|c|c|c|c|}
\hline \multirow{2}{*}{ Prefecture } & \multicolumn{5}{|c|}{ Free residual chlorine $(\mathrm{mg} / \mathrm{l})$} & \multirow{2}{*}{ Tota } \\
\hline & 0 & $0.1-0.2$ & $0.3-0.4$ & $40.5-0.6$ & $\mathrm{UN}^{*}$ & \\
\hline Miyagi & $1^{* *}$ & 0 & 0 & 0 & 0 & 1 \\
\hline Tokyo & 0 & 4 & 1 & 0 & 2 & 7 \\
\hline Kanagawa & 0 & 0 & 0 & 2 & 3 & 5 \\
\hline Chiba & 0 & 1 & 0 & 0 & 0 & 1 \\
\hline Saitama & 0 & 1 & 1 & 1 & 0 & 3 \\
\hline Gunma & 0 & 0 & 0 & 0 & 1 & 1 \\
\hline Ibaraki & 0 & 0 & 0 & 0 & 1 & 1 \\
\hline Nagano & 0 & 0 & 1 & 0 & 0 & 1 \\
\hline Shizuoka & 0 & 1 & 0 & 0 & 0 & 1 \\
\hline Osaka & 0 & 0 & 0 & 0 & 1 & 1 \\
\hline Tokushima & 0 & 1 & 0 & 0 & 0 & 1 \\
\hline Fukuoka & 0 & 0 & 1 & 0 & 0 & 1 \\
\hline Okinawa & 0 & 0 & 0 & 0 & 1 & 1 \\
\hline Total & 1 & 8 & 4 & 3 & 9 & 25 \\
\hline
\end{tabular}

which were formed by Gram-negative and positive rod-shaped bacteria were collected and stored at $-80^{\circ} \mathrm{C}$ (Table 1). The stored strains were cultured on R2A agar medium at $30^{\circ} \mathrm{C}$ for 7 days and used for further study.

\section{Biochemical tests}

20 biochemical properties were tested using API20NE (bioMériux, Marcy l'Etoile, France) following the protocol of the manufacturer. The results were analyzed using the analytical software, APIWAB Ver 1.1.0 (bioMériux).

\section{Identification by partial 16S rDNA sequence analysis}

Genomic DNA was extracted and purified by using the High Pure PCR Template Preparation Kit (Roche Diagnostics $\mathrm{GmbH}$, Mannheim, Germany) following the protocol of the manufacturer. Using the extracted DNA solution as the template for PCR, the 5 ' end partial region of $16 \mathrm{~S}$ rRNA gene (about $500 \mathrm{bp}$ ) was amplified using the MicroSeq 500 16S rDNA PCR Kit (Applied Biosystems, Foster City, CA, USA). The PCR products were purified using the Quantum Pre PCR Kleen Spin Columns (Bio-Rad Laboratories, Hercules, CA, USA). The sequencing reactions of the PCR products were performed using the MicroSeq 500165 rDNA sequencing Kit (Applied Biosystems) and the reaction products were purified with AutoSeq $^{\text {TM }}$ G-50 (Amersham Pharmacia Biotech, Inc., Uppsala, Sweden). A model ABI PRISM ${ }^{\circledR} 3100$ Genetic Analyzer (Applied Biosystems) was used for 
TABLE 2. Comparison of species identified by $16 \mathrm{~S}$ rDNA sequence analysis with those by using the API20NE system.

\begin{tabular}{cllll}
\hline Strains & $\begin{array}{l}\text { Species identified by 16S rDNA } \\
\text { sequence analysis }\end{array}$ & $\begin{array}{l}\text { Species identified by using the } \\
\text { API20NE system }\end{array}$ & API profile & \multirow{2}{*}{ ID \% } \\
\hline Y-2 & Sphingomonas ursincola/natatoria & Pasteurella sp. & 1000004 & 47.9 \\
Y-6 & Sphingomonas ursincola/natatoria & Aeromonas salmonicida & 1000204 & 60.9 \\
Y-7 & Sphingomonas ursincola/natatoria & Pasteurella sp. & 1000200 & 73.3 \\
Y-8 & Sphingomonas ursincola/natatoria & Moraxella sp. & 0000004 & 82.2 \\
Y-11 & Sphingomonas ursincola/natatoria & Acinetobacter lowffii & 0000200 & 38.4 \\
Y-13 & Sphingomonas ursincola/natatoria & Aeromonas salmonicida & 1040204 & 91.2 \\
Y-25 & Sphingomonas ursincola/natatoria & Brevundimonas vesicularis & 0000204 & 58.3 \\
Y-27 & Sphingomonas ursincola/natatoria & Comamonas testosteroni & 1204440 & 77.5 \\
Y-37 & Sphingomonas ursincola/natatoria & Unknown & 0000000 & \\
Y-56 & Sphingomonas ursincola/natatoria & Unknown & 0000000 & \\
Y-74 & Sphingomonas ursincola/natatoria & Aeromonas salmonicida & 1000204 & 60.9 \\
Y-81 & Sphingomonas ursincola/natatoria & Acinetobacter lowffii & 0000200 & 38.4 \\
Y-1 & Mycobacterium frederiksbergense & Comamonas testosteroni & 1004440 & 56.1 \\
Y-20 & Mycobacterium frederiksbergense & Unknown & 0005440 & \\
Y-10 & Sphingomonas adhaesiva & Sphingomonas paucimobilis & 0442164 & 78.0 \\
Y-44 & Sphingophyxis witflariensis & Brevundimonas vesicularis & 0400200 & 99.7 \\
Y-57 & Porphyrobacter donghaensis & Sphingomonas paucimobilis & 0062204 & 49.9 \\
Y-3 & Sphingomonas sp. & Unknown & 0000000 & \\
Y-5 & Sphingomonas sp. & Sphingomonas paucimobilis & 0463341 & 97.7 \\
Y-34 & Sphingomonas sp. & Pasteurella haemolytica & 0020004 & 84.6 \\
Y-63 & Sphingomonas sp. & Sphingomonas paucimobilis & 0461640 & 99.8 \\
Y-21 & Asticcacaulis sp. & Brevundimonas vesicularis & 0460205 & 52.3 \\
Y-38 & Asticcacaulis sp. & Brevundimonas vesicularis & 0440004 & 99.6 \\
Y-84 & Asticcacaulis sp. & Brevundimonas vesicularis & 0400000 & 78.6 \\
Y-51 & Novosphingobium sp. & Moraxella sp. & 0000004 & 82.2 \\
\hline
\end{tabular}

sample electrophoresis and data collection. The obtained sequence data were compared with reference data from GenBank/EMBL/DDBJ, and a phylogenetic tree was constructed by the neighbor-joining method of Saitou and Nei (1987). The isolated strains were identified on the basis of more than $99 \%$ similarity values that the same group or species showed.

\section{Chroline resistance tests}

As an assumption test, $10^{6} \mathrm{CFU} / \mathrm{ml}$ bacteria were exposed to $2 \mathrm{ml}$ of $0.1 \mathrm{mg} / \mathrm{I}$ residual free chlorine solution for 1 minute, followed by the immediate addition of $2 \mathrm{ml}$ of nutrient broth, for chlorine consumption. The bacteria were then kept at $30^{\circ} \mathrm{C}$ for 7 days, and the turbidity was observed. The CT value was measured as follows: Sodium hypochlorite dilutions were added to $200 \mathrm{ml}$ of sterile distilled water to prepare $0.1-1.0 \mathrm{mg} / \mathrm{l}$ experimental solutions. The test bacteria were cultured on R2A agar medium at $30^{\circ} \mathrm{C}$ for 5 days beforehand, and isolated colonies were suspended with sterile distilled water to preparea bacterial suspension of about $10^{8} \mathrm{CFU} / \mathrm{ml}$. The bacteria were seeded in the experimental solutions to adjust the concentration to $10^{6} \mathrm{CFU} / \mathrm{ml}$. After exposure to chlorine with stirring at room temperature for the specified time, $3 \mathrm{ml}$ of this solution was added to a sterile tube containing $50 \mu \mathrm{I}$ of $0.3 \mathrm{~N}$ sodium thiosulfate solution to neutralize the residual chlorine. After completion of the series of experiments, each solution was diluted, and $0.1 \mathrm{ml}$ was smeared on R2A agar medium and cultured at $30^{\circ} \mathrm{C}$ for 7 days, and the

TABLE 3. CT values (99.99\%) of yellow pigmented bacteria isolated from the tap water in hospitals.

\begin{tabular}{llc}
\hline Strains & \multicolumn{1}{c}{ Species } & CT value $(\mathrm{mg} \cdot \mathrm{min} / \mathrm{I})$ \\
\hline Y-1 & Mycobacterium frederiksbergense & 32 \\
Y-7 & Sphingomonas ursincola or S. natatoria & 3.3 \\
Y-5 & Sphingomonas sp. & 0.87 \\
Y-27 & Sphingomonas ursincola or S. natatoria & 0.45 \\
Y-21 & Asticcacaulis sp. & 0.095 \\
Y-10 & Sphingomonas adhaesiva & 0.03 \\
\hline
\end{tabular}






FIG. 1. Phylogenetic tree, based on neighbor-joining (Saitou and Nei, 1987), derived from an alignment comprising 16 $S$ rDNA 5' end partial reagion sequences (405bp). Brevundimonas subvibriodes (AJ227784) and Asticcacaulis taihuensis (AY500141) served as the out groups. The data set was resampled 1,000 times by using the bootstrap option and the percentage values are given at the nodes. The scale bar indicates the number of substitutions per nucleotide position. 


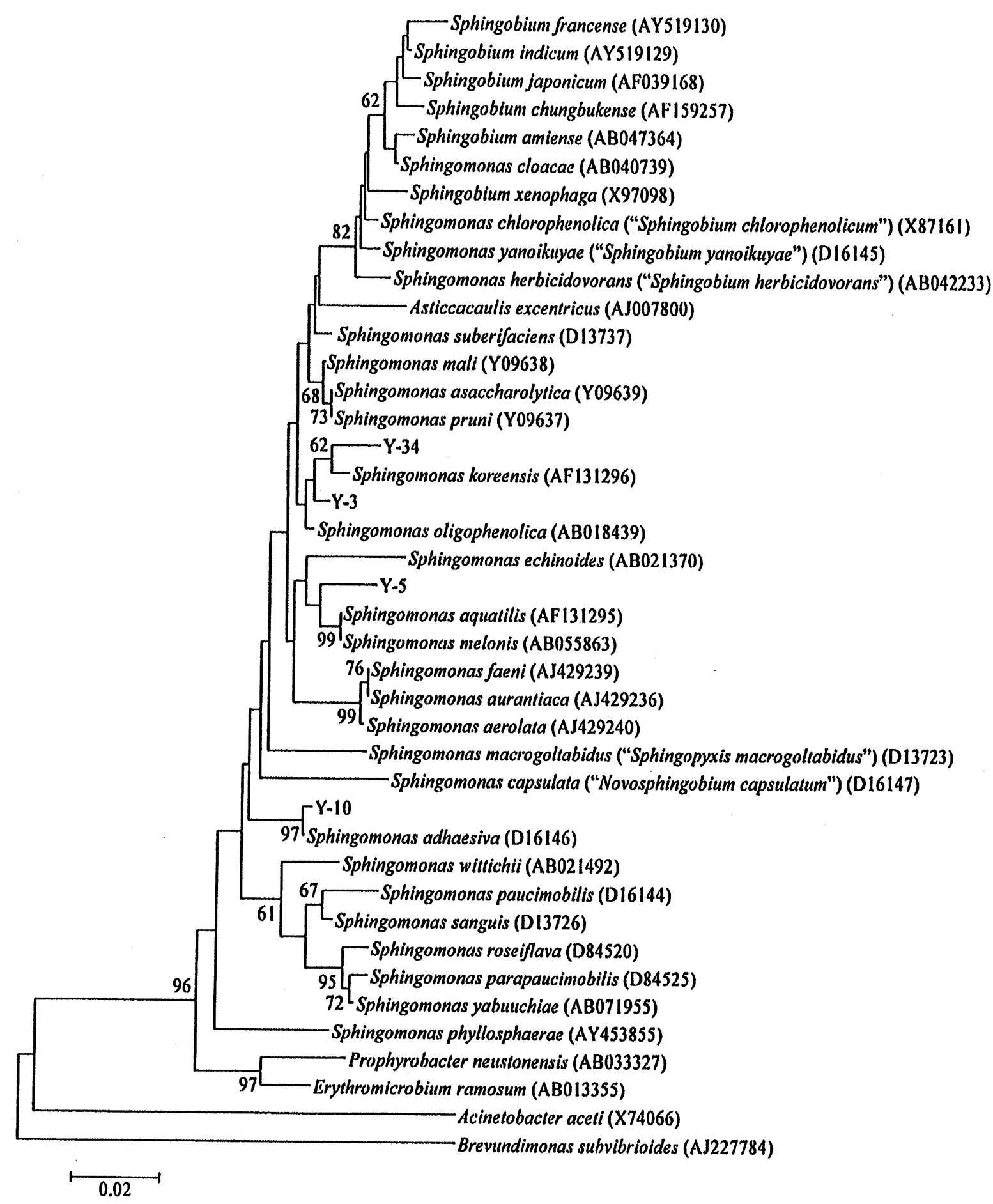

FIG. 2. Phylogenetic tree, based on neighbor-joining (Saitou and Nei, 1987), derived from an alignment comprising 16 S rDNA 5' end partial reagion sequences (406bp). Brevundimonas subvibriodes (AJ227784) served as the out group. The data set was resampled 1,000 times by using the bootstrap option and the percentage values are given at the nodes. The scale bar indicates the number of substitutions per nucleotide position. 


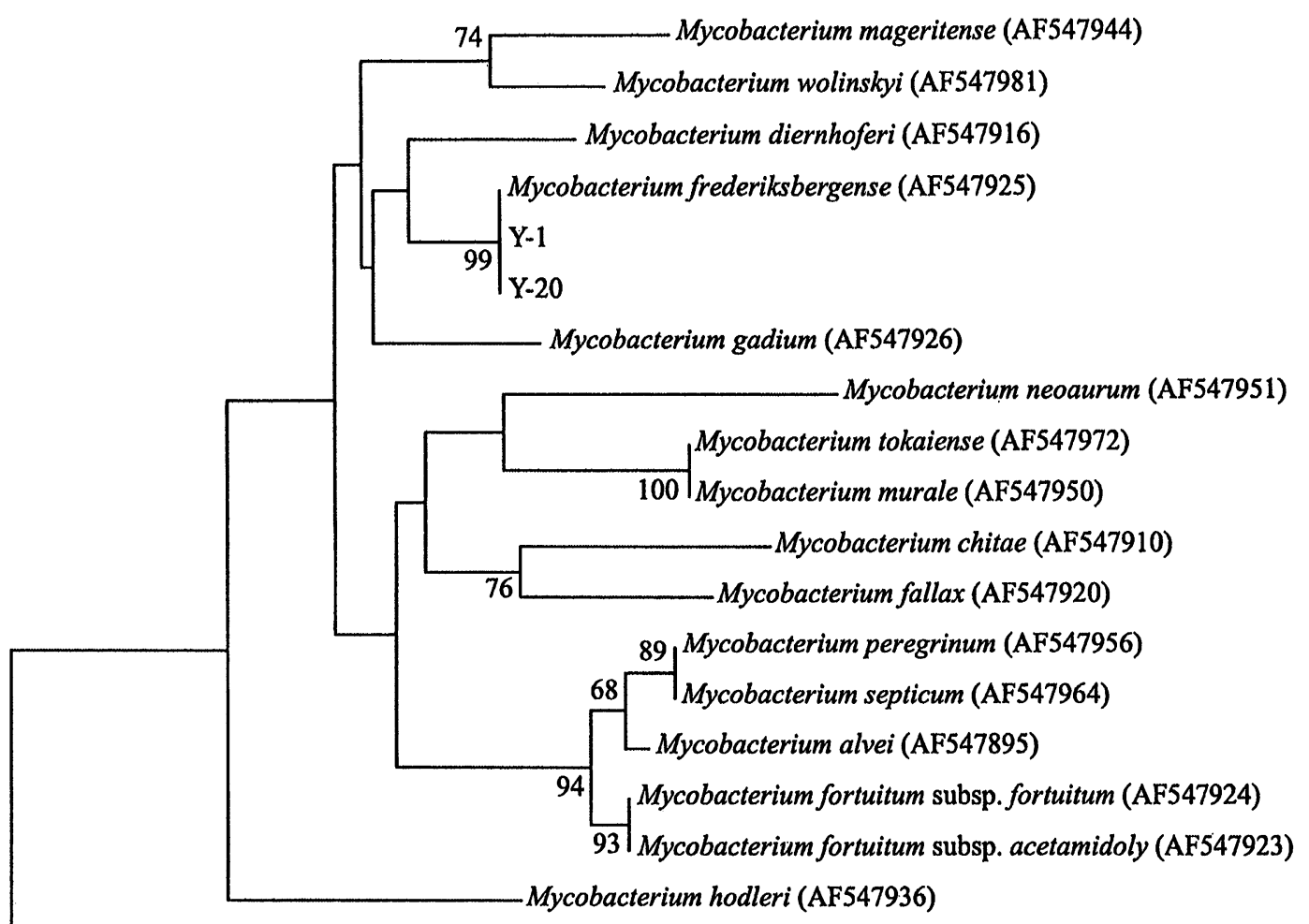

Nocardia abscessus (AY544980)

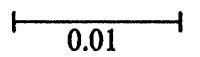

FIG. 3. Phylogenetic tree, based on neighbor-joining (Saitou and Nei, 1987), derived from an alignment comprising $16 \mathrm{~S}$ rDNA 5' end partial reagion sequences (439bp). Nocardia abscessus (AY544980) served as the out group. The data set was resampled 1,000 times by using the bootstrap option and the percentage values are given at the nodes. The scale bar indicates the number of substitutions per nucleotide position.

CFU were measured. The CT value was calculated by multiplying the residual chlorine concentration killing $99.99 \%$ of bacteria by the exposure time.

\section{RESULTS}

\section{Phylogenetic analysis of tap water-derived yel- low-pigmented bacteria by partial 16S rDNA se- quence analysis}

Phylogenetic trees based on the 16S rDNA sequences of the test strains and related bacteria are shown in Figs. 1-3. According to these trees, 12 isolates $(Y-2, Y-6, Y-7, Y-8, Y-11, Y-13, Y-25, Y-27, Y-$ 37, $Y-56, Y-74$ and $Y-81)$ belonged to the Sphingomonas ursincola and $S$. natatoria group. Three isolates (Y-21, Y-38 and Y-84) were most related to the previously known species of the genus Asticcacaulis with less than $97.0 \%$ similarity values, and those levels of similarity were novel species. $Y$ 44 was identified as Sphingopyxis witflariensis, and Y-57 was identified as Porphyrobacter donghaensis. Y-51 and Y-63 clustered with species of the genera Novosphingobium and Sphingomonas respectively.
$Y-10$ was clustered with Sphingomonas adhaesiva. Y-3, Y-5 and Y-34 clustered with Sphingomonas species, but they could not be identified clearly. $Y-1$ and Y-20 were identified as Mycobacterium frederiksbergense.

\section{Comparison with species identified by 165 rDNA sequence analysis and that of using the API20NE system}

The results of identification by $16 S$ rDNA sequence analysis are shown in Table 2. Twelve strains (48.0\%) were identified as Sphingomonas ursincola/ natatoria by the $16 \mathrm{~S}$ rDNA analysis, which was the highest population, followed by 2 strains (8.0\%) identified as Mycobacterium frederiksbergense. One strain each (4.0\%) was identified as Sphingomonas adhaesiva, Sphingopyxis witflariensis and Porphyrobacter donghaensis.

Some species identified using the API20NE system were shown in Table 2. When identification probability (ID\%) were more than $80 \%$, two strains each (8.0\%) were respectively identified as Brevundimonas vesicularis, Sphingomonas paucimobilis and 
Moraxella spp.. One strain each (4.0\%) was identified as Aeromonas salmonicida and Pasteurella haemolytica respectively. The other strains were not identified clearly.

The identification results by sequence analysis and biochemical property testing were not consistent in any of the strains, clarifying that accurate identification results cannot be obtained by biochemical property testing alone.

\section{Chlorine resistance of test strains}

When 25 isolates were exposed to $0.1 \mathrm{mg} / \mathrm{l}$ residual free chorine for 1 minute, the medium became turbid in 22 isolates (88.0\%), showing their survival. No turbidity of medium was noted in 3 strains (12.0\%), indicating that the bacteria were completely killed. Table 3 shows the $99.99 \%$ CT values of 6 strains. M.frederiksbergense ( $\mathrm{Y}-1$ strain) was most resistant to chlorine with the CT value of $32 \mathrm{mg} \cdot \mathrm{min} / \mathrm{l}$, followed by $S$. ursincola/natatoria ( $Y-7$ strain) with the $C T$ value of $3.3 \mathrm{mg} \cdot \mathrm{min} / \mathrm{l}$. The CT values of $\mathrm{Y}-5$ (Sphingomonas sp.), Y-27 (S. ursincola/natatoria) and $Y-21$ (Asticacaulis sp.) were within a range of 0.9-0.1 $\mathrm{mg} \cdot \mathrm{min} / \mathrm{l}$. Among the 6 strains, resistance of the Y-10 strain (S. adhaesiva) was the weakest, and the CT value was $0.03 \mathrm{mg} \cdot \mathrm{min} / \mathrm{l}$.

\section{DISCUSSION}

Out of oligotrophic bacteria isolated from hospital tap water, yellow chromogenic bacteria were subjected to identification, and many of these strains belonged to the gram-negative genus Sphingomonas. Although surveys of oligotrophic bacteria in tap water have been reported (Carter et al., 2000), no study has identified isolates in detail. Many oligotrophic bacterial strains produce various water-insoluble pigments, which are important properties for differentiation. Oligotrophic yellow chromogenic bacteria in tap water identified as Pseudomonas sp. (O'Brien, 1992) and Flavobacterium sp. (Reasoner, et al., 1989) based on the pigment colors have been reported, but our report is the first study which identifies the genus Sphingomonas. The most frequently identified species in this study, Sphingomonas ursincola/natatoria, was proposed as a new Sphingomonas species by Yabuuchi et al. (1999, 2002). A gram-positive bacteria, Mycobacterium frederiksbergense was also identified. M. frederiksbergense is an acid-fast bacterium newly named by Williumsen et al. (2001). Isolation of non-tuberculous mycobacteria from tap water has been reported (Miyamoto et al., 2000), and its influence is a health matter. Chang et al. (2002) detected non-tuberculous mycobacteria in hospital tap water at a rate of $20.4 \%$, showing the risk of infection in hospitals.

Chlorine resistance of isolates was also investigated in this study. Mir et al. (1997) compared the chlorine resistance of 6 isolates from water samples collected from water purification processes in which residual chlorine was present, and found that grampositive bacteria, such as Bacillus sp. and Micrococcus sp., were more resistant to chlorine than gram-negative Pseudomonas sp.. In our study, the CT value (99.99\%) of gram-positive $M$. frederiksbergense was the highest $(32 \mathrm{mg} \cdot \mathrm{min} / \mathrm{l})$, in good accordance with the findings reported by Mir et al. (1997). Since the CT value of $E$. coli was about 0.01 $\mathrm{mg} \cdot \mathrm{min} / \mathrm{I}$, the chlorine resistance of $M$. frederiksbergense may be more than 1,000 times that of $E$. coli. Strong chlorine resistance of acid-fast bacteria has been clarified by Grabow et al. (1983, 1984) They exposed $M$. fortuitum to $0.4 \mathrm{mg} / \mathrm{I}$ residual free chlorine for 15 minutes, but most of the seeded bacteria at $10^{3} \mathrm{CFU} / \mathrm{ml}$ were not killed. We previously reported that Methylobacterium widely present in tap water was relatively resistant to chlorine among gram-negative bacteria (Hiraishi et al., 1995; Furuhata et al., 2006). In the Sphingomonas spp. investigated in this study, the CT value (99.99\%) of some strains was $3.3 \mathrm{mg} \cdot \mathrm{min} / \mathrm{l}$, showing that their chlorine resistance was as strong as that of Methylobacterium, although the bacteria were gramnegative, and their isolation from tap water containing residual chlorine was convincing.

Kelley et al. (2004) recently detected Sphingomonas spp. on a shower curtain, and recommended its rapid removal in consideration of the possibility that it could be a pathogen causing opportunistic infection. When Oie et al. (2006) investigated microbial contamination of the ultrasonic nebulizer solution used in hospitals, Sphingomonas spp. was isolated. Thus, they recommended a thorough bactericidal treatment taking a shorter time. Similarly, the possibility of Sphingomonas spp. isolated from hospital tap water to cause opportunistic infection cannot be ruled out. Since complete elimination of this species from tap water is impossible at present, recognition of its presence in tap water, and specific considerations for handling tap water in hospitals are necessary.

\section{ACKNOWLEDGEMENT}

This work was supported in part by Health and Labour Sciences Research Grants (H18-Kenki-Ippan-008) from the Ministry of Health, Labour and Welfare. 


\section{REFERENCES}

Carter, J. T., Rice, E. W., Buchberger, S. G., and Lee, Y. (2000) Relationships between levels of heterotrophic bacteria and water quality parameters in a drinking water distribution system. Wat.Res., 34, 1495-1502.

Chang, C-T., Wang, L-Y., Liao, C-Y., and Huang, S-P. (2002) Identification of nontuberculous mycobacteria existing in tap water by PCR-restriction fragment length polymorphism. Appl. Environ. Microbiol., 68, 3159-3161.

Furuhata, K., and Fukuyama, M. (2006) Isolation of Oligotrophic Bacteria from Hospital Tap Water (in Japanese). Bokin Bobai, 34, 323-328.

Furuhata, K., Kato, Y., Goto, K., Hara, M., Yoshida, S., and Fukuyama, M. (2006) Isolation and identification of Methylobacterium species from the tap water in hospitals in Japan and their antibiotic susceptibility. Microbiol. Immunol., 50, 11-17.

Grabow, W. O. K., Gauss-Müller, V., Prozesky, O. W., and Deinhardt, F. (1983) Inactivation of Hepatitis A virus and indicator organisms in water by free residuals. Appl. Environ. Microbiol., 46, 619-624.

Grabow, W. O. K., Coubrough, P., Hilner, C., and Bateman, B. W. (1984) Inactivation of Hepatitis A virus, other enteric viruses and indicator organisms in water by chlorination. Wat. Sci. Tech., 17, 657-664.

Hiraishi, A., Furuhata, K., Matsumoto, A., Koike, K. A., Fukuyama, M., and Tabuchi, K. (1995) Phenotypic and genetic diversity of chlorine-resistant Methylobacterium strains isolated from various environments. Appl. Environ. Microbiol., 61, 2099-2107.

Holmes, B., Owen, R. J., Evans, A., Malnick, H., and Willcox, W. R. (1977) Pseudomonas paucimobilis, a new species isolated from human clinical specimens, the hospital environment, and other sources. Int. J. Syst. Bacteriol., 27, 133-146.

Kelley, S. T., Theisen, U., Angenent, L. T., Amand, A. St., and Pace, R. (2004) Molecular analysis of shower curtain biofilm microbes. Appl. Environ. Microbiol., 70, 41874192.
Mir, J., Morató, J. and Ribas, F. (1997) Resistance to chlorine of freshwater bacteria strains. J. Appl. Microbiol., 82, 7-18.

Miyamoto, M., Yamaguchi, Y., and Sasatsu, M. (2000) Distribution of Legionella and nontuberculous mycobacteria in environment (in Japanese). Kankyokansen, 15, 127-132.

O'Brien, J. R. (1992) An unusual yellow pigmented Pseudomonas species isolated from chlorinated municipal town water supply. Microbios, 69, 215-221.

Oie, S., Makieda, D., Ishida, S., Okano, Y., and Kamiya, A. (2006) Microbial contamination of nebulization solution and its measures. Biol. Pharm. Bull., 29, 503-507.

Reasoner, D. J., Balannon, J. C., Geldreich, E. E., and Barnick, J. (1989) Nonphotosynthetic pigmented bacteria in a potable water treatment and distribution system. Appl. Environ. Microbiol., 55, 912-921.

Saitou, N., and Nei, M. (1987) The neighbor-joining method: A new method for reconstructing phylogenetic trees. Mol. Biol. Evol., 4, 406-425.

Willumsen, P., Karlson, U., Stackebrandt, E., and Kroppenstedt, R. M. (2001) Mycobacterium frederiksbergense sp. nov., a novel polycyclic aromatic hydrocarbon-degrading Mycobacterium species. Int. J. Syst. Evol. Microbiol., 51, 1715-1722.

Yabuuchi, E., Kosako, Y., Naka, T., Suzuki, S., and Yano, I. (1999) Proposal of Sphingomonas suberifaciens (van Bruggen, Jochimsen and Brown 1990) comb. nov., Sphingomonas natatoria (Sly 1985) comb. nov. Sphingomonas ursincola (Yurkov et al. 1997) comb. nov., and emendation of the genus Sphingomonas. Microbiol. Immunol., 43, 339-349.

Yabuuchi, E., Kosako, Y., Fujiwara, N., Naka, T. Matsunaga, I., Ogura, H., and Kobayashi, K. (2002) Emendation of the genus Sphingomonas Yabuuchi et al. 1990 and junior objective synonymy of the species of three genera, Sphingobium, Novosphingobium and Sphingopyxis, in conjunction with Blastomonas ursincola. Int. J. Syst. Evol. Microbiol., 52, 1485-1496. 